Aus dem Institut für Infektionskrankheiten „Robert Koch“ in Berlin. (Direktor: Geh. Ober-Med.-Rat Prof. Gaffky.)

\section{Serologische Untersuchungen über den Antigengehalt der Kulturlösungen von Tuberkelbazillen.)}

\section{Von Stabsarzt Prof. Dr. B. Möllers in Straßburg i. E.}

Im Zusammenhang mit den vorstehend geschilderten chemischen Untersuchungen des Herrn Prof. Lockemann stellte ich an dem gleichen Untersuchungsmaterial Versuche an, den Antigengehalt der verschiedenen Kulturlösungen im Verlauf des Wachstums der Tuberkelbazillen auch auf serologischem Wege zu verfolgen und zu kontrollieren.

Bekanntlich gestattet die vor etwa zehn Jahren in die wissenschaftliche Technik durch Bordet und Geng ou eingeführte Komplementbindungsmethode, den Antigengehalt eines Bakterienextraktes, in unserem Falle der verschiedenen Tuberkulinlösungen gegenüber einem spezifischen, reichliche Antikörper enthaltenden Serum, zahlenmäßig darzustellen.

Als antikörperhaltiges Serum benutzten wir ein von den Höchster Farbwerken uns freundlichst überlassenes Tuberkuloseserum, über dessen Gewinnungsweise und Eigenschaften Ruppel und Rieckmann ${ }^{2}$ ) näher berichtet haben. Bezüglich der im Tuberkuloselaboratorium des Instituts ,Robert Koch“ üblichen Technik der Komplementbindungsversuche sei auf die entsprechenden Ausführungen im 3. Heft der ,,Veröffentlichungen der Robert Koch-Stiftung": Möllers und Heine man n, ,, Ueber die stomachale Anwendung von Tuberkulinpräparaten" (S. 39) hingewiesen.

Um möglichst einwandfreie Resultate zu erhalten, wurden die Komplementbindungsversuche in verschiedenen Variationen und an verschiedenen Tagen wiederholt angestellt. Die Bewertung der verschiedenen Kulturlösungen mittels der Komplementbindungsmethode wurde in der Weise vorgenommen, da $ß$ zu fallenden Dosen der Tuberkulinlösung eine gleichbleibende Serumdosis $(0,01 \mathrm{ccm})$ zugesetzt wurde und dadurch der jedesmalige Antigengehalt im Vergleich zu einem Standardtuberkulin (Alttuberkulin Höchst Nr. 34) festgestellt wurde.

Bei der Anstellung des Hauptversuches wurde ferner Wert darauf gelegt, daß eine möglichst große Zahl der verschiedenen Tuberkulinlösungen an dem gleichen Tage mit dem gleichen Tuberkuloseserum und hämolytischen System und zusammen mit dem Standardtuberkulin untersucht wurden.

$\mathrm{Zu}$ unseren Versuchen benutzten wir dieselben Tuberkulinlösungen wie Professor Lockemann, die teils aus GlyzerinBouillon, teils aus albumosefreien Asparagin-Nährböden durch Einengen auf ein Viertel der ursprünglichen Flüssigkeitsmenge hergestellt waren.

Um zur Beurteilung der Komplementbindungsuntersuchungen brauchbare Durchschnittswerte zu erhalten, wurden sowohl bei dem Glyzerin-Bouillon- als auch bei dem Asparagin-Nährboden die Ergebnisse von je drei Untersuchungen zusammengestellt und hieraus die Mittelwerte berechnet.

Vergleichen wir den Verlauf der Gewichtskurve mit der Kurve des Antigengehaltes, so fällt ohne weiteres die große Aehnlichkeit beider Kurven in die Augen. Der Antigengehalt nimmt bei beiden Nährmedien zunächst von Woche zu Woche zu mit dem zunehmenden Gewicht der Kulturen und erreicht in der fünften bis sechsten Woche seinen Höhepunkt. Von der achten Woche an wird dann der Antigengehalt der Kulturlösungen erheblich geringer, während gleichzeitig das Gewicht der Kultur abnimmt, allerdings in einem verhältnismäßig geringerem Grade.

Der Ausfall dieses Versuchs läßt einige Schlußfolgerungen zu über den Ursprung der spezifischen Substanz des Tuberkulins, welche teilweise als ein Stoffwechselprodukt der lebenden Bazillen angesehen wird, teilweise als ein von den abgestorbenen Tuberkelbazillen herrührendes Auslaugungsprodukt. Wäre nun das letztere der Fall, so müßten wir mit zunehmender Zeit

1) Die Untersuchungen wurden mit den Mitteln der Robert KochStiftung ausgeführt und werden demnächst in den Veröffentlichungen dieser Stiftung ausführlich mitgeteilt.

$\left.{ }^{2}\right)$ Zeitschrift für Immunitätsforschung 1910, Bd. 6, H. 2 u. 3. des Verweilens der Kulturlösungen im Brutschrank eine ansteigende Kurve des Antigengehaltes erhalten, da man auf Grund der später eintretenden Abnahme des Gewichts der Tuberkelkulturen annehmen mu $\beta$, da $\beta \mathrm{z}$. B. in der 10.-12. Woche ein erheblich stärkeres Absterben und Auslaugen der Bazillen stattfindet als in der 3.-5. Woche.

Würde anderseits die spezifische Substanz des Tuberkulins hauptsächlich ein Produkt der wachsenden Bazillen darstellen, so müßte man anfangs bis zur sechsten Woche, so lange eine Gewichtsvermehrung der Kulturen eintritt, ein starkes Ansteigen des Antigengehaltes beobachten, wie es auch tatsächlich der Fall ist. Im weiteren Verlaufe des Wachstums der Tuberkelbazillen nach der sechsten Woche müßte man dann erwarten, da $\beta$ der Antigengehalt auf der gleichen Höhe stehen bliebe wie vorher, was jedoch nicht zutrifft. Wir beobachten vielmehr bei beiden Nährmedien nach der achten Woche ein deutliches Fallen des Antigengehaltes, während von der zehnten Woche an sich die Kurve auf ungefähr der gleichen Höhe hält, wie auch durch weitere Versuche bestätigt wird, deren nähere Ausführung hier zu weit führon würde.

Die Abnahme des Antigengehaltes nach der sechsten bzw. achten Woche läßt sich am einfachsten durch die Annahme erklären, da $§$ um diese Zeit ein dem Antigen schädlicher Stoff in der Lösung entsteht. Dabei muß die Frage offen bleiben, ob der schädigende Einflu $ß$ durch eine Auslaugung der Tuberkelbazillen oder durch autolytische Vorgänge bedingt wird.

Aus den angegebenen Daten läßt sich der Schluß ziehen, daß der Verlauf der Antigenkurve weder einzig durch Stoffwechselprodukte der wachsenden Tuberkelbazillen, noch allein durch Auslaugungsprodukte der abgestorbenen Bazillen bedingt wird, sondern dass offenbar beide Faktoren gleichzeitig daran beteiligt sind. Die Stoffwechseltätigkeit der wachsenden Tuberkelbazillen is t offenbar die Hauptursache des Auftretens der spezifischen Substanz des Tuberkulins, während dem Auslaugungsprozeß möglicherweise eine den Antigengehalt schädigende Wirkung zukommt.

Der Antigengehalt ist bei dem aus Bouillonnährboden hergestellten Tuberkulin während der ganzen Dauer des Wachstums der Tuberkelbazillen höher als bei dem in absolut gleicher Weise behandelten Asparagin-Nährboden, obwohl die Gewichtskurven der auf beiden Nährböden gewachsenen Kulturmassen im großen ganzen übereinstimmen.

Aus diesem verschiedenen Verhalten läßt sich natürlich nicht ohne weiteres der Schluß ziehen, da $B$ das aus dem Bouillon-Nährboden hergestellte sogenannte Alttuberkulin dem aus dem AsparaginNährboden dargestellten albumosefreien Tuberkulin (Tuberkulin A. F.) vorzuziehen sei, da Bedeutung und Herkunft der im Komplementbindungsversuch nachweisbaren Antikörper noch nicht genügend geklärt sind. Die beiden käuflichen Tuberkulinpräparate werden übrigens so dargestellt, daß sie sowohl bei der Prüfung am tuberkulösen Meerschweinchen wie im Komplementbindungsversuch gleichmäßige Werte zeigen.

Eine praktische Schlu Bfolgerung, die aus unseren Versuchen gezogen werden könnte, ist wohl die, daß es zur Herstellung eines wirksamen Tuberkulins nicht notwendig und zweckmä Big ist, die Tuberkelbazillen monatelang auf dem betreffenden Nährboden wachsen zu lassen, da das Ma xi mu m des Antigengehaltes, soweit es sich wenigstens auf dem Wege des Komplementbindungsversuches ermitteln läßt, bereits $n$ ach sechswöchigem Wachstum der Bazillen erreicht wird.

Zusammenfassung. 1. Der durch den Komplementbindungsversuch nachweisbare Antigengehalt der Kulturlösungen von Tuberkelbazillen nimmt gleichzeitig mit dem Wachstum der Kulturen bis zur sechsten Woche zu, wird aber nach der achten Wachstumswoche wieder geringer.

2. Als hauptsächliche Ursache des Auftretens der spezifischen Substanz des Tuberkulins müssen wir die Stoffwechseltätigkeit der wachsenden Tuberkelbazillen ansehen, während dem Auslaugungsproze $B$ möglicherweise eine den Antigengehalt beeinträchtigende Wirkung zukommt. 
3. Der Verlauf der Gewichtskurve der Tuberkelbazillen auf flüssigen Nährböden zeigt eine große Aehnlichkeit mit der Kurve des Antigengehalts der entsprechenden Kulturflüssigkeiten. 